\title{
False-positive dengue serology in a patient of coronavirus disease 2019
}

\author{
Rahul Diip Agrawal ${ }^{1}$, Dipi Agrazwal ${ }^{2}$ \\ From ${ }^{1}$ Cardiologist, ${ }^{2}$ Echocardiographer, Department of Cardiology, Anandrishiji Hospital, Ahmednagar, Maharashtra, India
}

\begin{abstract}
Dengue and coronavirus disease 2019 (COVID-19) both are currently prevalent in India, more so due to the ongoing monsoon season. In such a scenario, it is imperative to distinguish between the two, as both share many similarities in a clinical presentation such as fever and myalgia. Herein, we describe a case of elderly gentleman, aged 68 years, who presented to the emergency department with complaints of dyspnea and chest pain. On evaluation, he had dengue IgM positive with NS1 antigen negative. Later on, he was diagnosed as false positive. The patient was found to be COVID positive on reverse transcription polymerase chain reaction. This case illustrates the importance of differentiating between COVID-19 and dengue.
\end{abstract}

Key words: Coronavirus disease 2019, Dengue, Dengue serology

$\mathrm{D}$ engue and novel coronavirus disease 2019 (COVID19) both are currently prevalent in India, more so due to the ongoing monsoon season. In such a scenario, it is imperative to distinguish between the two, as both share many similarities in a clinical presentation such as fever and myalgia [1].

Herein, we describe the case of a 68-year-old gentleman who presented with dyspnea and chest pain. On evaluation, he had dengue IgM positive with NS1 antigen negative. Later, he was diagnosed as false positive. The patient was found to be COVID positive on reverse transcription polymerase chain reaction (RT-PCR).

\section{CASE REPORT}

A 68-year-old man with a previous history of hypertension for 15 years presented to the emergency department with complaints of tightness in the chest and difficulty in breathing at around 10 A.M. There was no evident history of fever.

The patient had a blood pressure of $210 / 130 \mathrm{mmHg}$ and oxygen saturation of $92 \%$ with a respiratory rate of around $36 / \mathrm{min}$ and a heart rate of $98 / \mathrm{min}$. Due to the blood oxygen saturation level on the lower side and in view of the current COVID-19 scenario, he was hospitalized and kept in the isolation unit in ICU with a possible diagnosis of the left ventricular failure.

A 12-lead electrocardiogram done was suggestive of the left ventricular hypertrophy (LVH) with normal sinus rhythm. The

\section{Access this article online}

Received - 26 August 2020

Initial Review - 10 September 2020

Accepted - 19 October 2020

DOI: $10.32677 /$ IJCR.2020.v06.i10.017 chest X-ray was normal. Transthoracic echocardiography was suggestive of a normal ejection fraction with no regional wall motion abnormality and a mild LVH.

The patient settled after giving IV furosemide and nitroglycerine. Oxygen saturation was normalized with highflow oxygen at $6 \mathrm{~L} / \mathrm{mi}$. However, the patient developed a fever spike of 103 degrees Fahrenheit in the evening. Hence, a fever profile was sent and a high-resolution computed tomography (HRCT) scan of the chest was performed. The blood investigations revealed hemoglobin of $15.9 \mathrm{~g} / \mathrm{dl}$, total leukocyte count of $61,000 /$ cubic $\mathrm{mm}$, and platelet counts of 1.69 lacs/cubic mm. Troponin T was negative. Serum creatinine level was $1.3 \mathrm{mg} / \mathrm{dL}$. C-reactive protein was $9.98 \mathrm{mg} / \mathrm{L}$. Serum electrolytes $(\mathrm{Na}=140 \mathrm{meq} / \mathrm{L}, \mathrm{K}=4.11 \mathrm{meq} / \mathrm{L})$ were normal. Serum CPK MB levels were normal( 20 IU per L). Dengue serology was suggestive of $\operatorname{IgM}$ antibody positive with a negative NS1 antigen and IgG antibody. All laboratory parameters as mentioned above were in the normal range. HRCT thorax was suggestive of viral pneumonitis (Fig. 1). This raised suspicion in our minds and we went on to test COVID-19 by RT-PCR swab test.

Meanwhile, suspecting COVID-19, the patient was started on IV dexamethasone, IV antibiotics, and oral paracetamol if the temperature was more than $100^{\circ} \mathrm{F}$, amlodipine, and diuretics. Oxygen therapy was continued at $6 \mathrm{~L} / \mathrm{min}$ by a mask. The patient settled with the above treatment and was moved out of the ICU on the $3^{\text {rd }}$ day of admission. His RT-PCR report for COVID-19 came positive, and hence, the patient was shifted to a dedicated COVID care center on that very day for further management.

Correspondence to: Rahul Diip Agrawal, Department of Cardiology, Anandrishiji Hospital and Medical Research Center, Ahmednagar, Maharashtra, India. E-mail: rahul.d.agrawal@gmail.com

(C) 2020 Creative Commons Attribution-NonCommercial 4.0 International License (CC BY-NC-ND 4.0). 


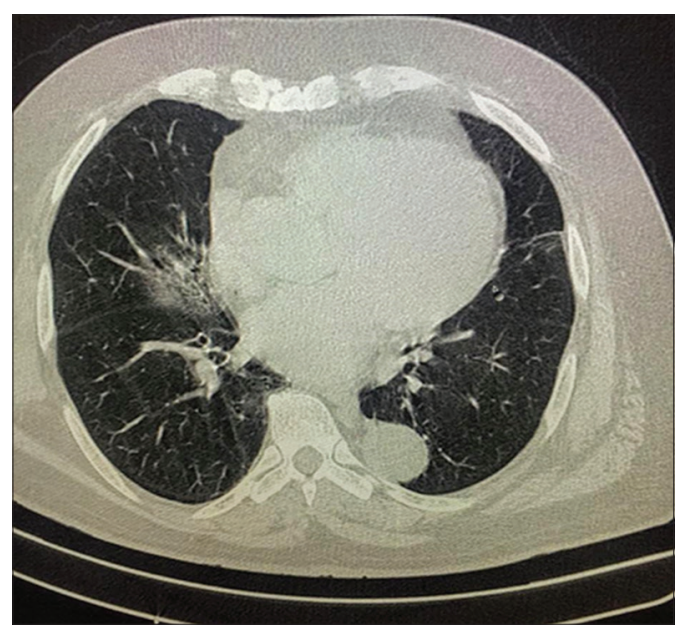

Figure 1: High-resolution computed tomography scan showing small consolidation in the middle lobe

On follow-up of the patient in the COVID center, we found that he was given injection remdesivir, to which he responded well and was doing better now. The patient responded well to treatmeny. His oxygen requirement was 6 litres/min via mask, which gradually decreased and he was weaned off from oxygen over a period of 2 weeks. He will be discharged soon.

\section{DISCUSSION}

The first serosurvey by the Indian Council of Medical Research in the country estimated the national prevalence of the novel coronavirus infections at the time to be $0.73 \%$ of the population and an infection fatality rate to be of $0.08 \%$ [2]. The current status of COVID-19 as per the Ministry of Health and Family Welfare as of October 10, 2020, is as follows: Number of active cases $-883,185$, discharged $-5,988,822$, and deaths $-107,416[3]$.

Dengue is endemic in India. The estimated number of dengue infections among individuals aged 5-45 years from 30 Indian states in 2017 was $12,991,357(12,825,128-13,130,258)$ based on the constant force of infection models [2]. At present, there is an unprecedented strain on health-care systems worldwide. In the near future, the overlap of COVID-19 and dengue epidemics is a concrete threat in tropical regions [4,5]. COVID-19 and dengue share several features of clinical and laboratory presentation, and differential diagnosis should rely on specific diagnostic tests [6]. This highlights the need to differentiate between false-positive dengue serology and COVID-19. Recently, two false-positive cases of false-positive results by rapid diagnostic test for dengue in patients with SARSCoV-2 infection were reported from Singapore [7,8]. The cases from Singapore highlight the importance of recognizing falsepositive dangle serology results (with different commercially available assays) in patients with COVID-19 [7]. Ours is the first such reported case from India.

Since the beginning of this pandemic, COVID-19 is hard to solve the puzzle for doctors and scientists all around the globe.
Adding antigen mimicry to this complex puzzle has quite significant public health implications. If such patients are falsely diagnosed as dengue, it could lead to infection among health-care staff and hence the spread of disease [9]. If serological crossreactivity between patients with COVID-19 and dengue will be confirmed, it may result in a high number of misdiagnosis, with dangerous consequences both from the patient and from the public health point of view [10].

In low- and middle-income countries where arbovirus and other common tropical diseases are highly endemic, the SARS-CoV-2 spread will represent an additional challenge for clinicians [11,12]. In particular, coepidemics of COVID-19 and dengue could be an overwhelming situation for health systems [13].

COVID-19 is a new illness. Each day is met with new discoveries and surprises. With each passing day, we are becoming wiser as to what to look for and what to anticipate and this has led to significant improvements in case management. In both dengue and COVID-19, if treatment is initiated early the patient responds well and thus the future complications are avoided. Therefore, a correct diagnosis is very important.

\section{CONCLUSION}

Dengue is endemic in India with more prevalence in rainy season. Both dengue and COVID-19 are viral illnesses and share many similar clinical features. In such a scenario, it is imperative to differentiate between the two since both have vastly different management protocols and public health implications. Our case highlights the importance of being vigilant so as to keep in mind both these as differential diagnosis when dealing with a patient presenting with fever and myalgia.

\section{REFERENCES}

1. Ratnarathon AC, Pongpirul K, Pongpirul WA, Charoenpong L, Prasithsirikul W. Potential dual dengue and SARS-CoV-2 infection in Thailand: A case study. Heliyon 2020;6:e04175.

2. ICMR's First Sero-Survey Paper Out: India Missed 81 Infections per Case in May, 11/09/2020. The Wire Staff as Published in Science the Wire. Available from: https://www.science.thewire.in/the-sciences/icmr-seroprevalencesurvey-paper-published-ifr-case-load-increase-seropositivity. [Last accessed on 2020 May 10].

3. The Website of Ministry of Health and Family Welfare, MOHFW, Government of India; COVID-19 INDIA. Available from: https://www. mohfw.gov.in $/$ index1.php?lang $=1$ level $=1$ sublinkid $=6471$ lid $=4270 . \quad$ [Last accessed on 2020 Oct 10].

4. Navarro JC, Arrivillaga-Henríquez J, Salazar-Loor J, Rodriguez-Morales AJ. COVID-19 and dengue, co-epidemics in Ecuador and other countries in Latin America: Pushing strained health care systems over the edge. Travel Med Infect Dis 2020;37:101656.

5. Lorenz C, Azevedo TS, Chiaravalloti-Neto F. COVID-19 and dengue fever: A dangerous combination for the health system in Brazil. Travel Med Infect Dis 2020;35:101659.

6. Lam LT, Chua YX, Tan DH. Roles and challenges of primary care physicians facing a dual outbreak of COVID-19 and dengue in Singapore. Fam Pract 2020;37:578-9.

7. Yan G, Lee CK, Lam LT, Yan B, Chua YX, Lim AY, et al. Covert COVID-19 and false-positive dengue serology in Singapore. Lancet Infect Dis 2020;20:536.

8. Prasitsirikul W, Pongpirul K, Pongpirul WA, Panitantum N, Ratnarathon AC, 
Hemachudha T. Nurse infected with Covid-19 from a provisional dengue patient. Emerg Microbes Infect 2020;9:1354-5.

9. Li R, Pei S, Chen B, Song Y, Zhang T, Yang W, et al. Substantial undocumented infection facilitates the rapid dissemination of novel coronavirus (SARS-CoV-2). Science 2020;368:489-93.

10. Bokhari SM, Mahmood F, Bokhari SM. Case report: Diagnosis of COVID-19 versus tropical diseases in Pakistan. Am J Trop Med Hyg 2020;103:77-8.

11. Joob B, Wiwanitkit V. COVID-19 can present with a rash and be mistaken for dengue. J Am Acad Dermatol 2020;82:e177.

12. Wu D, Lu J, Liu Q, Ma X, He W. To alert coinfection of COVID-19 and dengue virus in developing countries in the dengue-endemic area. Infect
Control Hosp Epidemiol 2020;1:Doi: https://doi.org/10.1017/ice.2020.187.

13. Wilder-Smith A, Rupali P. Estimating the dengue burden in India. Lancet Glob Health 2019;7:e988-9.

Funding: None; Conflicts of Interest: None Stated.

How to cite this article: Agrawal RD, Agrawal D. False-positive dengue serology in a patient of coronavirus disease 2019. Indian J Case Reports. 2020;6(10):598-600. 